\title{
Propagation of Nuclear Data Uncertainties in Transmutation Calculations Using ACAB Code
}

\author{
O. Cabellos* and N. García-Herranz \\ Instituto de Fusión Nuclear, Universidad Politécnica de Madrid, 28006 Madrid, Spain and \\ Departamento de Ingeniería Nuclear, Universidad Politécnica de Madrid, 28006 Madrid, Spain \\ Carlos J. Diez de LA OBRA and R. Alvarez-CAscos \\ Departamento de Ingeniería Nuclear, Universidad Politécnica de Madrid, 28006 Madrid, Spain \\ J. SANZ \\ Instituto de Fusión Nuclear, Universidad Politécnica de Madrid, 28006 Madrid, Spain and \\ Departamento de Ingeniería Energética, Universidad Nacional de Educación a Distancia (UNED), 28004 Madrid, Spain \\ F. Ogando and P. SAUVAN \\ Departamento de Ingeniería Energética, Universidad Nacional de Educación a Distancia (UNED), 28004 Madrid, Spain
}

(Received 26 April 2010)

\begin{abstract}
The assessment of the accuracy of parameters related to the reactor core performance (e.g., keff) and fuel cycle (e.g., isotopic evolution/transmutation) due to the uncertainties in the basic nuclear data (ND) is a critical issue. Different error propagation techniques (adjoint/forward sensitivity analysis procedures and/or Monte Carlo technique) can be used to address by computational simulation the systematic propagation of uncertainties on the final parameters. To perform this uncertainty assessment, the ENDF covariance files (variance/correlation in energy and crossreactions-isotopes correlations) are required.

In this paper, we assess the impact of ND uncertainties on the isotopic prediction for a conceptual design of a modular European Facility for Industrial Transmutation (EFIT) for a discharge burnup of $150 \mathrm{GWd} / \mathrm{tHM}$. The complete set of uncertainty data for cross sections (EAF2007/UN, SCALE6.0/COVA-44G), radioactive decay and fission yield data (JEFF-3.1.1) are processed and used in ACAB code.
\end{abstract}

PACS numbers: 21.60.Ka, 24.10.Lx

Keywords: Uncertainty propagation, Uncertainty nuclear data, Transmutation, ADS

DOI: $10.3938 / \mathrm{jkps} .59 .1268$

\section{INTRODUCTION}

An extensive work on ND needs for innovative power reactors and fuel cycles has been performed by a wellrecognized expert group of OECD/NEA WPEC Subgroup 26 [1] and by a group working in the NUDATRA domain IP-EUROTRANS [2]. They have identified and independently corroborated a number of highest-priority isotopes/reactions for fast systems and waste minimization technologies. More recently, the ANDES project (Accurate Nuclear Data for Nuclear Energy Sustainability) within Euratom Call FP7-Fission-2009, has been guided by these studies for the selection of the specific actions of nuclear developments. In recent years, it has also been recognized by the ND international community that an additional effort for further provision of covari-

*E-mail: oscar.cabellos@upm.es ance data is needed using methodologies to evaluate the uncertainties and covariance matrices from experimental data and nuclear models.

One of the objectives in ANDES project is to improve inventory codes, such as ACAB code [3] (NEA-1839), to handle the complete set of uncertainty/covariance data (i.e., those of nuclear reactions, radioactive decay and fission yield data). This paper presents the potential benefit of full uncertainty propagation techniques through the inventory calculations in transmutation systems.

\section{PROBLEM DEFINITION}

The basic characteristics of the industrial-scale transmutation facility EFIT [2] are: core cooled by pure lead, thermal power $400 \mathrm{MW}$, initial total mass of actinides 2.074 tonnes $(21.7 \%$ MA, fuel initial composition shown 
in Table 1), and 150 GWd/tHM discharge burn-up corresponding to an equilibrium cycle ( $\sim 78$ irradiation days).

In the calculations, a constant neutron environment representative of the equilibrium cycle is assumed throughout irradiation period (spectrum average energy $<\mathrm{E}>=0.375 \mathrm{MeV}$ and flux intensity $3.12 \times 10^{15}$ $\left.\mathrm{n} / \mathrm{cm}^{2} \cdot \mathrm{s}\right)$. With this irradiation conditions, a burn-up of $150 \mathrm{GWd} / \mathrm{tHM}$ is reached at 778 days. The assumed neutron flux and spectrum have been taken from fully detailed 3D burn-up calculations performed with EVOLCODE2 code [4], and correspond to a representative cell in the inner part of the core at mid-burnup.

\section{Basic Nuclear Data}

The ND basic libraries used in this problem are the following: (i) the multigroup activation neutron crosssection basic library EAF_N_XS-2007 [5], (ii) the decay data basic library JEFF-3.1.1 [6], and (iii) the fission yield basic library, JEFF-3.1.1[6].

The decay and fission yield uncertainty data have been taken and processed from JEFF-3.1.1. The neutron cross-section uncertainty data have been taken from the EAF-2007/UN [5] library and SCALE6.0/COVA$44 \mathrm{G}[7]$.

EAF2007/UN contains uncertainty information for all the reactions and isotopes potentially present in the irradiated fuel. Its main characteristics are: (i) below 20 $\mathrm{MeV}$, the energy spectrum is divided in three energy groups for nuclear reactions without threshold and in one group for reactions with threshold; (ii) all type of correlations between different isotopes and reactions are neglected, (iii) errors between all bands inside a certain energy group are 100\% correlated, and errors between different energy groups are $0 \%$ correlated; iv) the uncertainty values stored in the library are $\Delta_{\mathrm{j}, \mathrm{EAF}}^{2}(j$ is the energy group), which can be interpreted as the uncertainty (or relative error) in the standard or best-estimate cross section, stored in the corresponding standard activation library. For this analysis, the values of $\Delta_{\mathrm{j}, \mathrm{EAF}}$ are taken as three times the experimental uncertainty, that is, $\Delta_{\mathrm{j}, \mathrm{EAF}}=3^{*} \Delta_{\mathrm{j}, \mathrm{EXP}}$. ZZ-SCALE6.0/COVA-44G is a 44-group cross section covariance matrix library retrieved from the SCALE-6.0 package. This covariance library is based on several different uncertainty approximations with varying degrees of " fidelity" to the present ND evaluation. The library includes evaluated covariances obtained from ENDF/B-VII, ENDF/B-VI, and JENDL3.3. Correlations between different isotopes and reactions are included.

\section{PROPAGATION OF UNCERTAINTIES: SENSITIVITY ANALYSIS AND MONTE CARLO METHOD}

Let $\mathbf{N}(\mathrm{t})=\left(\mathrm{N}_{1}(\mathrm{t}), \mathrm{N}_{2}(\mathrm{t}), \ldots, \mathrm{N}_{\mathrm{M}}(\mathrm{t})\right)^{\mathrm{T}}$ be the nuclide composition of a material, consisting of $\mathrm{M}$ nuclides, at time t. The set of differential equations which describe the evolution of $\mathbf{N}$ in a neutron field may be written in matrix notation

$$
\frac{d N(t)}{d t}=A N=[\lambda] N+\left[\sigma^{e f f}\right] \Phi N+\left[\left(\gamma \sigma_{f i s s}\right)^{e f f}\right] \Phi N
$$

where $\boldsymbol{A}$ is the transition matrix involving one-group effective cross sections $\left[\sigma^{\text {eff }}\right]$, one-group effective fission yield cross sections $\left[\left(\gamma \sigma_{\text {fiss }}\right)^{\text {eff }}\right]$ and decay values $[\lambda] . \Phi$ is the space-energy integrated neutron flux. Given the initial nuclide density vector as $\mathbf{N}_{0}=\mathbf{N}(0)$, the solution is $\mathbf{N}(\mathrm{t})=\exp (\boldsymbol{A} \mathrm{t}) \mathbf{N}_{0}$.

In this work, we assume no uncertainties in: (i) the initial nuclide density, (ii) the integrated neutron flux, (iii) and the flux spectrum. In summary, the sources of uncertainty in this transmutation calculation are only due to basic input ND.

For a given neutron environment, we can define the corresponding one-group effective cross sections, $\sigma^{\text {eff }}$. Let $\left[\varphi_{1}, \varphi_{2}, \ldots, \varphi_{G}\right]$ be the values of the flux corresponding to each energy group; then, the spectrum-averaged cross section is obtained as: $\sigma^{e f f}=\frac{\varphi_{1} \sigma_{1}+\varphi_{2} \sigma_{2}+\cdots+\varphi_{G} \sigma_{G}}{\varphi_{1}+\varphi_{2}+\cdots+\varphi_{G}}$.

Given $\boldsymbol{V}$, the $\mathrm{G}$-by-G relative variance matrix of the cross sections, the variance $\Delta^{2}$ of the relative spectrumaveraged cross section is $\Delta^{2}=\omega^{T} V \omega$, with $\omega=$ $\left[\frac{\varphi_{1}}{\bar{\varphi}} \frac{\sigma_{1}}{\sigma^{e f f}}, \cdots, \frac{\varphi_{G}}{\bar{\varphi}} \frac{\sigma_{G}}{\sigma^{e f f}}\right]^{T}$ and the total flux as $\bar{\varphi}=\varphi_{1}+$ $\varphi_{2}+\cdots+\varphi_{G}$. In inventory calculations, this procedure to derive one-group covariance data guaranties that the uncertainty on any nuclide density using different energy group structure remains constant.

The effective fission product yield $\gamma^{\text {eff }}$, defined as the spectrum-averaged fission yield for formation of nuclei $i$ by fission in the nuclei $j$ can be expressed as

$$
\gamma_{j, i}^{e f f}=\frac{\gamma_{1}^{j, i} \sigma_{1}^{f i s s, j} \varphi_{1}+\ldots+\gamma_{G}^{j, i} \sigma_{G}^{f i s s, j} \varphi_{G}}{\sigma_{1}^{f i s s, j} \varphi_{1}+\ldots+\sigma_{G}^{f i s s, j} \varphi_{G}}
$$

where, $\gamma_{\mathrm{g}}^{\mathrm{j}, \mathrm{i}}$ is the probability that a type- $i$ nuclide will be formed as a fission product by absorption of a neutron of energy group- $g$ by a nuclide of type- $j$, and $\sigma_{\mathrm{g}}^{f i s s, j}$ is the microscopic fission cross section of type- $j$ nuclei for energy group- $g$. The variance of this value is calculated weighting the variance of the fission yield as in Eq. (2).

Nuclear decay data (half-lives and branching ratios) and its variance were processed directly from the nuclear decay data library JEFF-3.1.1.

\section{Sensitivity/uncertainty analysis}

We define a random vector $\alpha=\left(\sigma^{\text {eff }}, \lambda, \gamma^{\text {eff }}\right)$ containing all the cross sections, decays and fission yields involved in the problem. Each concentration at time $t$, $\mathbf{N}(\mathrm{t})$, is a function of the random vector $\alpha$. The first order Taylor series provides a means of approximating $\mathbf{N}\left(\sigma^{\text {eff }}, \lambda, \gamma^{\text {eff }}\right)$ about $\left(\hat{\sigma}^{\text {eff }}, \hat{\lambda}, \hat{\gamma}^{\text {eff }}\right)$, that is assumed to be the best-estimated ND vector. 
Let $\boldsymbol{S}$ be the M-by-R matrix containing the sensitivity coefficients $\left(\rho_{\mathrm{ij}}\right)$ of the M-isotopic concentrations with respect to the one-group cross sections, fission yields and decay data, $\rho_{i j}=\frac{\hat{\alpha}_{j}}{\hat{N}_{i}}\left[\frac{\partial N_{i}}{\partial \alpha_{j}}\right]_{\hat{\alpha}}$. The variation in the concentrations of the $\mathrm{M}$ nuclides can be expressed as $\mathbf{N}(\alpha)$ $\mathbf{N}(\hat{\alpha}) \approx \boldsymbol{S} \varepsilon$, where $\varepsilon=\alpha-\hat{\alpha}$. The variance of the nuclide concentrations can be evaluated as follows: $\operatorname{var}(\mathbf{N}) \approx \boldsymbol{S}$ $[\mathrm{COV} \alpha] \boldsymbol{S}^{\mathbf{T}}$.

\section{Monte Carlo method}

Other methodology to perform uncertainty analysis is random simulation or Monte Carlo (MC) method. To apply this methodology, information about the joint probability distribution of the ND errors is necessary. Different assumptions can be made about the probability distribution; the simplest and more usual (in many other areas) is the normal distribution. An alternative distribution is the $\log$ normal, that is, $\log (\alpha / \hat{\alpha}) \rightarrow N(0, V)$, where $\boldsymbol{V}$ is the variance matrix of the ND relative error.

When correlations in cross sections between different isotopes and reactions are introduced, the usual Cholesky decomposition method is used. Letting $\boldsymbol{P}$ that verify $\boldsymbol{V}=\boldsymbol{P} \boldsymbol{P}^{\mathrm{T}}$, it can be proven that the same joint probability values are obtained as follows: (i) Generate $\mathrm{Z}=\left(\mathrm{Z}_{1}, \mathrm{Z}_{2}, \ldots\right)^{\mathrm{T}}$ independent $\mathrm{N}(0,1)$ random variables, (ii) define $\mathrm{Y}=\boldsymbol{P Z}, \mathrm{Y}=\left(\mathrm{Y}_{1}, \mathrm{Y}_{2}, \ldots\right)^{\mathrm{T}}$, and (iii) for every variable we estimate $\alpha=\hat{\alpha} \cdot \exp (Y)$.

The inventory code $\mathrm{ACAB}$ is used to propagate the overall ND set. To sample each ND component of $\alpha$ separately, a sample size of 1000 histories was found appropriated.

\section{UNCERTAINTIES IN THE ISOTOPIC INVENTORY: IMPACT OF NUCLEAR DATA UNCERTAINTIES}

In this section, we provide a confident set of uncertainty estimates for EFIT at a discharge burn-up of 150 GWd/tHM. A set of nuclides (light elements, actinides and fission products) were designated as the most relevant due to either transmutation or importance in the response functions (e.g., decay heat, neutron emission, public dose).

\section{Actinides at the end of the irradiation}

The nominal variation (without uncertainties) of the actinide concentrations at the end of irradiation is shown in Table 1. Uncertainty values of the final concentration due to decay data uncertainty $(\lambda \mathrm{s}), \mathrm{JEFF}-3.1 .1$, and cross section (XS) uncertainty data, EAF2007/UN and SCALE6.0, are computed by MC approach.

Sensitivity calculations have been performed in order to identify the reactions whose cross section uncertainties have a major impact on the concentration uncertainty. Table 2 shows a summary of this calculation.
Table 1. Initial actinide composition $(\mathrm{Ni})$, nominal variation $\left(\mathrm{N}_{\mathrm{f}}-\mathrm{N}_{\mathrm{i}}\right)$ and uncertainty (relative error in \%) in the final concentration $\left(\mathrm{N}_{\mathrm{f}}\right)$ for actinides at $150 \mathrm{GWd} / \mathrm{tHM}$.

\begin{tabular}{|c|c|c|c|c|c|}
\hline \multirow[b]{2}{*}{ Nuclide } & \multirow[b]{2}{*}{$\begin{array}{l}\mathrm{N}_{\mathrm{i}} \\
\text { [\#atoms] }\end{array}$} & \multirow[b]{2}{*}{$\begin{array}{l}\mathbf{N}_{\mathbf{f}}-\mathbf{N}_{\mathrm{i}} \\
{[\# \text { atoms] }}\end{array}$} & \multicolumn{3}{|c|}{$\begin{array}{l}\text { Uncertainty [\%] } \\
\text { due to: }\end{array}$} \\
\hline & & & $\lambda \mathbf{s}$ & $\begin{array}{l}\text { XS } \\
\text { EAF }\end{array}$ & $\begin{array}{l}\text { XS } \\
\text { SCALE }\end{array}$ \\
\hline${ }^{232} \mathrm{U}$ & - & $4.37 \mathrm{E}+20$ & 5.2 & 9.8 & 1.0 \\
\hline${ }^{233} \mathrm{U}$ & - & $1.57 \mathrm{E}+21$ & 0.1 & 12.6 & 14.9 \\
\hline${ }^{234} \mathrm{U}$ & $7.67 \mathrm{E}+25$ & $6.79 \mathrm{E}+25$ & 0.0 & 4.6 & 1.9 \\
\hline${ }^{235} \mathrm{U}$ & $1.84 \mathrm{E}+25$ & $1.83 \mathrm{E}+25$ & 0.0 & 13.2 & 3.0 \\
\hline${ }^{236} \mathrm{U}$ & $2.54 \mathrm{E}+25$ & $2.46 \mathrm{E}+25$ & 0.0 & 1.8 & 2.3 \\
\hline${ }^{237} \mathrm{U}$ & $2.33 \mathrm{E}+18$ & $4.07 \mathrm{E}+22$ & 0.1 & 7.9 & 3.5 \\
\hline${ }^{238} \mathrm{U}$ & $1.30 \mathrm{E}+23$ & $1.27 \mathrm{E}+23$ & 0.0 & 1.3 & 2.2 \\
\hline${ }^{237} \mathrm{~Np}$ & $2.25 \mathrm{E}+26$ & $1.39 \mathrm{E}+26$ & 0.0 & 6.1 & 1.4 \\
\hline${ }^{238} \mathrm{~Np}$ & $6.07 \mathrm{E}+18$ & $2.40 \mathrm{E}+23$ & 0.1 & 7.8 & 1.8 \\
\hline${ }^{239} \mathrm{~Np}$ & $2.75 \mathrm{E}+20$ & $5.67 \mathrm{E}+20$ & 0.2 & 16.3 & 15.9 \\
\hline${ }^{238} \mathrm{Pu}$ & $4.26 \mathrm{E}+26$ & $3.99 \mathrm{E}+26$ & 0.0 & 4.3 & 2.5 \\
\hline${ }^{239} \mathrm{Pu}$ & $5.21 \mathrm{E}+26$ & $3.50 \mathrm{E}+26$ & 0.0 & 4.8 & 1.3 \\
\hline${ }^{240} \mathrm{Pu}$ & $1.73 \mathrm{E}+27$ & $1.44 \mathrm{E}+27$ & 0.0 & 1.9 & 0.3 \\
\hline${ }^{241} \mathrm{Pu}$ & $3.13 \mathrm{E}+26$ & $3.01 \mathrm{E}+26$ & 0.0 & 8.3 & 0.9 \\
\hline${ }^{242} \mathrm{Pu}$ & $7.50 \mathrm{E}+26$ & $6.77 \mathrm{E}+26$ & 0.0 & 2.2 & 0.7 \\
\hline${ }^{244} \mathrm{Pu}$ & $1.55 \mathrm{E}+23$ & $1.83 \mathrm{E}+23$ & 0.0 & 4.0 & 2.2 \\
\hline${ }^{241} \mathrm{Am}$ & $3.50 \mathrm{E}+26$ & $2.25 \mathrm{E}+26$ & 0.0 & 7.0 & 2.0 \\
\hline${ }^{242} \mathrm{Am}$ & $3.81 \mathrm{E}+20$ & $1.31 \mathrm{E}+23$ & 0.2 & 8.6 & 2.6 \\
\hline${ }^{242 \mathrm{~m}} \mathrm{Am}$ & $2.96 \mathrm{E}+25$ & $1.81 \mathrm{E}+25$ & 0.0 & 12.8 & 6.4 \\
\hline${ }^{243} \mathrm{Am}$ & $3.14 \mathrm{E}+26$ & $2.78 \mathrm{E}+26$ & 0.0 & 6.1 & 1.4 \\
\hline${ }^{242} \mathrm{Cm}$ & $3.17 \mathrm{E}+23$ & $2.64 \mathrm{E}+25$ & 0.1 & 10.4 & 3.4 \\
\hline${ }^{243} \mathrm{Cm}$ & $3.10 \mathrm{E}+24$ & $3.64 \mathrm{E}+24$ & 0.2 & 23.4 & 11.7 \\
\hline${ }^{244} \mathrm{Cm}$ & $2.67 \mathrm{E}+26$ & $2.92 \mathrm{E}+26$ & 0.0 & 6.2 & 3.1 \\
\hline${ }^{245} \mathrm{Cm}$ & $7.82 \mathrm{E}+25$ & $7.57 \mathrm{E}+25$ & 0.0 & 13.2 & 9.7 \\
\hline${ }^{246} \mathrm{Cm}$ & $5.20 \mathrm{E}+25$ & $5.19 \mathrm{E}+25$ & 0.0 & 7.3 & 3.5 \\
\hline${ }^{247} \mathrm{Cm}$ & $1.12 \mathrm{E}+25$ & $1.11 \mathrm{E}+25$ & 0.0 & 15.7 & 11.0 \\
\hline${ }^{248} \mathrm{Cm}$ & $8.33 \mathrm{E}+24$ & $8.79 \mathrm{E}+24$ & 0.0 & 6.6 & 4.3 \\
\hline${ }^{249} \mathrm{Bk}$ & - & $3.28 \mathrm{E}+23$ & 1.0 & 20.2 & 17.3 \\
\hline${ }^{249} \mathrm{Cf}$ & - & $2.72 \mathrm{E}+23$ & 1.1 & 20.4 & 17.9 \\
\hline${ }^{250} \mathrm{Cf}$ & - & $8.42 \mathrm{E}+22$ & 0.4 & 30.6 & 24.2 \\
\hline${ }^{251} \mathrm{Cf}$ & - & $5.03 \mathrm{E}+21$ & 0.3 & 44.0 & 30.3 \\
\hline${ }^{252} \mathrm{Cf}$ & - & $1.03 \mathrm{E}+20$ & 0.3 & 56.4 & 35.6 \\
\hline
\end{tabular}

Columns 2 and 3 show the one-group cross-section relative error from SCALE6.0 and EAF2007/UN. Following columns show the sensitivity coefficient $\left(\rho_{\mathrm{ij}}\right)$ for the amount of nuclide- $j$ due to the relative changes in cross section- $i$. In addition, total uncertainty of nuclide $\mathrm{N}_{\mathrm{j}}$ is computed using these libraries.

\section{Fission products at the end of the irradiation}

Uncertainty values of fission products due to decay data uncertainty and fission yield taken from JEFF-3.1.1, and cross section uncertainty data from 
Table 2. Sensitivity coefficients $\left(\rho_{\mathrm{ij}}\right)$, one- group XS relative error (in \%) and total uncertainty (in \%) of nuclides at $150 \mathrm{GWd} / \mathrm{tHM}$.

\begin{tabular}{l|l|l|l|l|l|l}
\hline \hline \multirow{2}{*}{ Reaction } & \multicolumn{2}{|l|}{$\begin{array}{l}\Delta X S \\
\text { err. }[\%]\end{array}$} & \multicolumn{4}{l}{$\begin{array}{l}\text { Sensitivity coefficient } \\
{\left[\rho_{\mathrm{ij}}\right]}\end{array}$} \\
\cline { 2 - 8 } & EAF & SCALE & $\mathrm{U}^{234}$ & $\mathrm{U}^{235}$ & $\mathrm{U}^{236}$ & $\ldots$ \\
\hline $\mathrm{U}^{234}(n, \gamma)$ & 38.9 & 6.9 & -0.07 & 0.21 & 0.01 & $\ldots$ \\
\hline $\mathrm{U}^{234}(n$, fiss $)$ & 16.5 & 30.0 & -0.06 & -0.01 & 0.00 & $\ldots$ \\
\hline $\mathrm{U}^{235}(n, \gamma)$ & 11.3 & 21.8 & 0.00 & -0.11 & 0.09 & $\ldots$ \\
\hline $\mathrm{U}^{235}(n$, fiss $)$ & 12.9 & 0.4 & 0.00 & -0.35 & -0.02 & $\ldots$ \\
\hline $\mathrm{U}^{236}(n, \gamma)$ & 8.9 & 3.1 & 0.00 & 0.00 & -0.12 & $\ldots$ \\
\hline$\ldots$ & $\ldots$ & $\ldots$ & $\ldots$ & $\ldots$ & $\ldots$ & $\ldots$ \\
\hline $\mathrm{U}^{235}($ fiss- $n, \gamma)$ & - & -0.3 & & & & \\
\hline $\mathrm{Pu}^{239}($ fiss- $n, \gamma)$ & - & 0.2 & & & & \\
\hline$\ldots$ & & $\ldots$ & & & & \\
\hline & & & & & & \\
\hline \multirow{2}{*}{ Total uncertainty } & SCALE & 1.9 & 2.7 & 2.1 & $\ldots$ \\
\hline & EAF07 & 4.0 & 12.2 & 1.6 & $\ldots$ \\
\hline \hline
\end{tabular}

Table 3. Uncertainty (relative error in \%) in the final concentration $\left(\mathrm{N}_{\mathrm{f}}\right)$ for fission products at $150 \mathrm{GWd} / \mathrm{tHM}$

\begin{tabular}{|c|c|c|c|c|c|}
\hline \multirow[b]{2}{*}{ Nuclide } & \multirow[b]{2}{*}{$\begin{array}{l}\mathbf{N}_{\mathbf{f}} \\
\text { [\#atoms] }\end{array}$} & \multicolumn{3}{|c|}{ Uncertainty in \% } & \multirow{2}{*}{$\begin{array}{l}\text { due to } \\
\text { XS } \\
\text { SCALE }\end{array}$} \\
\hline & & $\overline{\lambda \mathbf{s}}$ & $\gamma \mathbf{s}$ & $\begin{array}{l}\text { XS } \\
\text { EAF }\end{array}$ & \\
\hline${ }^{79} \mathrm{Se}$ & $2.25 \mathrm{E}+23$ & 0.00 & 5.9 & 4.3 & 1.6 \\
\hline${ }^{93 \mathrm{M}} \mathrm{Nb}$ & $1.81 \mathrm{E}+19$ & 6.19 & 2.9 & 3.5 & 1.3 \\
\hline${ }^{94} \mathrm{Nb}$ & $1.39 \mathrm{E}+20$ & 0.03 & 5.9 & 17.6 & 4.6 \\
\hline${ }^{93} \mathrm{Mo}$ & $1.45 \mathrm{E}+18$ & 0.01 & 2.7 & 82.6 & 1.2 \\
\hline${ }^{103} \mathrm{Rh}$ & $5.52 \mathrm{E}+25$ & 0.00 & 3.7 & 5.2 & 1.7 \\
\hline${ }^{107} \mathrm{Pd}$ & $3.52 \mathrm{E}+25$ & 0.01 & 4.0 & 4.9 & 2.3 \\
\hline${ }^{109} \mathrm{Ag}$ & $2.09 \mathrm{E}+25$ & 0.02 & 3.9 & 5.4 & 2.7 \\
\hline${ }^{126} \mathrm{Sn}$ & $2.02 \mathrm{E}+24$ & 0.00 & 7.2 & 4.8 & 2.1 \\
\hline${ }^{126} \mathrm{Sb}$ & $2.90 \mathrm{E}+21$ & 5.21 & 9.2 & 9.0 & 3.3 \\
\hline${ }^{126 \mathrm{M}} \mathrm{Sb}$ & $4.43 \mathrm{E}+18$ & 1.05 & 7.5 & 16.4 & 1. 9 \\
\hline${ }^{129} \mathrm{I}$ & $1.06 \mathrm{E}+25$ & 0.07 & 4.1 & 4.7 & 2.1 \\
\hline${ }^{149} \mathrm{Sm}$ & $9.68 \mathrm{E}+24$ & 0.00 & 3.6 & 6. 8 & 4.5 \\
\hline${ }^{150} \mathrm{Sm}$ & $4.57 \mathrm{E}+24$ & 0.01 & 3.0 & 11.0 & 7.7 \\
\hline${ }^{151} \mathrm{Sm}$ & $5.11 \mathrm{E}+24$ & 0.05 & 4.2 & 10.9 & 6.7 \\
\hline${ }^{152} \mathrm{Sm}$ & $8.94 \mathrm{E}+24$ & 0.01 & 3.1 & 6.6 & 4.0 \\
\hline${ }^{151} \mathrm{Eu}$ & $3.74 \mathrm{E}+22$ & 6.66 & 3.8 & 9.8 & 6.5 \\
\hline${ }^{153} \mathrm{Eu}$ & $3.65 \mathrm{E}+24$ & 0.01 & 4.4 & 14.6 & 5.2 \\
\hline${ }^{155} \mathrm{Gd}$ & $2.87 \mathrm{E}+23$ & 0.26 & 7.1 & 7.8 & 3.8 \\
\hline
\end{tabular}

EAF2007/UN and SCALE6.0 are computed by MC approach. Table 3 shows nuclides with a global uncertainty value above $6 \%$.

\section{CONCLUSIONS}

We have illustrated the potential benefit of full uncertainty propagation in transmutation calculations, and we have shown that: (i) decay uncertainties have a negligible effect on the isotopic prediction both in actinides and fission products, (ii) uncertainty in fission products due to fission yields remains below $10 \%$, and (iii) larger uncertainties were found due to cross section uncertainties. Regarding uncertainty data for cross sections, we conclude that: (i) EAF2007 seems to be very conservative; (ii) the relevant correlations between different isotopes and reactions are negligible. Total uncertainties obtained with the sensitivity methodology (Table 2) can be compared with those obtained with the MC methodology (Table 1). A very good agreement between both methodologies is found, demonstrating for this case the validity of the implicit linear approximation used in the sensitivity method. Calculations for extended irradiation time will be performed to assess the importance of ND uncertainties.

\section{ACKNOWLEDGMENTS}

Work performed under the auspices of the Spanish National Research Programme: Project ENE200907572, FP7-EURATOM-FISSION-2009:Project ANDES/249671 and CSN/UPM Agreement P090531725 on Burnup Credit Criticality Safety.

\section{REFERENCES}

[1] M. Salvatores et al., NEA/WPEC-26, OECD/NEA, 2008.

[2] N. García-Herranz et al., Ann. Nucl. Energy 37, 1570 (2010).

[3] J. Sanz, O. Cabellos and N. García-Herranz, NEA-1839, NEA Data Bank, 2008.

[4] F. Álvarez-Velarde, P. T. León and E. M. GonzálezRomero, in Proceedings of 9th Information Exchange Meeting on Actinide and Fission Product PETT, ISBN 97892-64-99030-2 (Nîmes, France, 2007).

[5] R. A. Forrest, UKAEA FUS 533, 2007.

[6] A. Santamarina et al., JEFF Report 22, OECD/NEA Data Bank, 2009.

[7] ZZ SCALE6.0/COVA-44G, 44-group cross section covariance matrix library extracted from SCALE6.0, USCD1236/02 Package. OECD/NEA Data Bank, 2009. 